

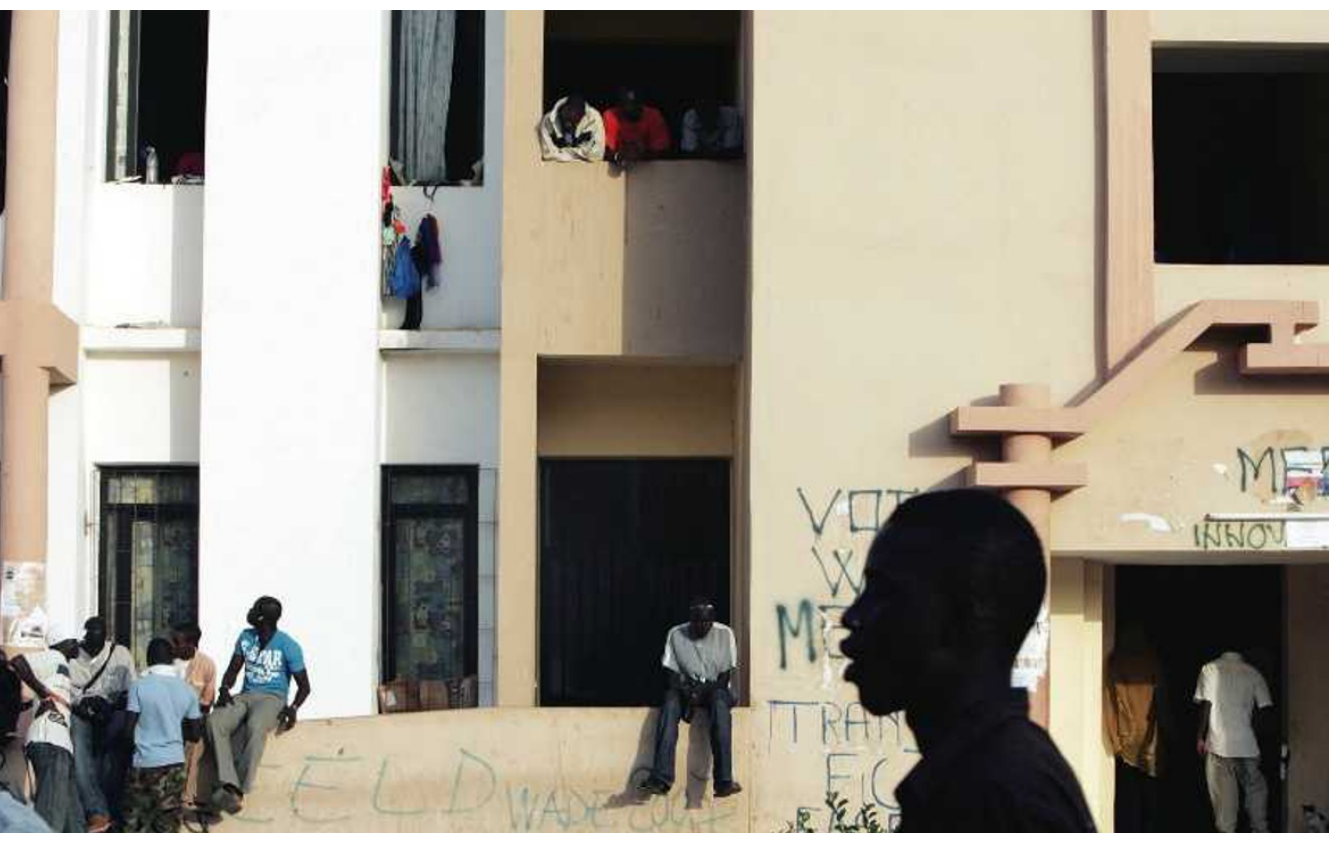

RUTH FREMSON/THE NEW YORK TIMES/CONTRASTO

from public universities whom they attract with higher salaries. For example, except for the director, the 11 members of the mathematics faculty at Eduardo Mondlane University also teach at private institutions. This doubling up on teaching responsibilities further reduces faculty time for research and mentoring. Nigeria has some 30 new private universities. Ghana has six public and 10 private universities, all founded within the past decade.

\section{SYSTEMIC APPROACH}

The situation for higher education in Africa might look bleak, but it is far from hopeless. Most institutions recognize the challenges they face, and some have begun to reform their policies. For example, to help address the country's chronic skills shortage, Zambia is considering eliminating the mandatory retirement age of 55 years for faculty in the sciences. The University of Nairobi has doubled faculty salaries twice in the past 8 years.

As universities and donor organizations increase efforts to bolster basic higher education, it is important to remember that S\&T will not by itself be sufficient to meet Africa's daunting challenges. We have seen how the rapid growth of the 'Asian tigers' in the 1970s and 1980s was not initiated by endemic research strength, but by imported technology. Basic research was emphasized only after a sound technological base had been created. The development of excellent primary and secondary school systems and broad-based training for faculty (often through study abroad) also provided a sturdy foundation upon which to build excellence in the basic sciences.

African leaders recognize that efforts to strengthen national capabilities in S\&T depend on a systemic approach. A conference held in Arusha, Tanzania, in May 2008 adopted the slogan of "mainstreaming STI into the develop- ment process". Conference organizers saw their objective as strengthening not only S\&T, but also 'innovation'.

I have worked for nearly a decade with the Science Initiative Group (SIG), based in Princeton, New Jersey, USA. SIG members are drawn from Brazil, India, South Korea, Sudan and the USA. In seeking to build S\&T capacity in developing countries, we have carefully examined other development models. Foremost among these are those of TWAS and several programmes originating in northern Europe, especially Sweden's International Science Programme (ISP).

Each of these programmes contains at least four major elements designed to develop systemic - not just academic - capacity: local leadership, a national innovation system, government support, and extensive networking with other institutions and the international scientific community. This approach focuses not only on the creation of knowledge, but also on fostering an environment in which knowledge is disseminated, used and transformed into new products and services.

Scientists and engineers from developing countries are best qualified to identify and address urgent national challenges. Governments are best situated to set general priorities, including aspects of S\&T. Instead of determining research topics and strategies abroad, successful programmes depend on national and local leaders for capacity building, education and research.

S\&T adds value to society only if it is part of a 'national innovation system' that increases the ability of a nation's institutions and infrastructure to create and commercialize new products for economic and societal use. Major elements of such a system include the following: human resources, including a national commitment to education at all levels; government institutions that sustain basic research, legal structures and physical infrastructure; and an entrepreneurial environment that nurtures small start-up firms, protects intellectual property and promotes the creation of venture capital.

An early goal of such a system, especially for poor countries with underutilized natural resources, is to create more value-added exports. As the private sector gains strength, other aspects of the innovation system will grow in importance. In sub-Saharan Africa outside South Africa,

countries have few small-sized and medium-sized enterprises, which can only thrive in a supportive environment. It is essential to begin planning for them by developing support mechanisms and laying the groundwork for technology-intensive clusters of academia, government and private enterprise that have proven so powerful for scientifically advanced countries.

Government enthusiasm for S\&T-based development is crucial. This includes support at the presidential and ministerial levels, especially at ministries of finance. A significant example is the US\$35-million Millennium Science Initiative in scientific research and education funded by the World Bank in Uganda. The priority status given to the programme by President Museveni and the Ministry of Finance provided early momentum to the effort, the primary objectives of which are to develop human resources and infrastructure for research, with complementary attention to university-industry linkages and support services.

Similarly, Rwanda has adopted an ambitious S\&T development programme, thanks largely to the personal involvement of President Kagame. Last winter, the president told a session of the American Association for the Advancement of Science (AAAS) meeting in Boston: "I believe in the power of science to transform our societies. But in Rwanda our institutions remain feeble. We have neither a strong private sector for demand, nor institutions to meet that demand. But we do have the will. For 7 years we have been laying a sound foundation for S\&T. The public sector will play a leading role while other pillars gain strength." Rwanda now spends $1.6 \%$ of its gross domestic product (GDP) on S\&T, and plans to increase this to $5 \%$ by 2021 .

Other governments in Africa are beginning to display commitment to S\&T. At the Arusha conference, Tanzania's Minister of Science and Technology, Peter Msolla, said his government "is determined to invest in STI" by focusing on research and development, retaining talent at home, and forging partnerships abroad. The responsibility for success, he stated, "lies primarily with national governments".

Even the best universities in sub-Saharan Africa lack a critical mass of students and faculty in fields of S\&T. While these universities might have the will to build capacity, it will take time and resources to attract and train new students and faculty. A valuable complementary strategy is to link these scientists with related institutions and their peers in Africa and around the world.

The ISP's success, based on more than 45 years of experience, has emphasized long-term support for fellowships, equipment purchases 
and locally requested fields of study. It has curbed brain drain by the use of a 'sandwich model' that offers 1-year visits to Uppsala, Sweden, as long as the recipient remains affiliated with his or her home institution, where the degree is conferred. Lennart Hasselgren, who initiated the ISP's programmes that now include chemistry, mathematics and physics, emphasizes the need for long-term support. ISP, for example, has funded one group for 32 years. Annual grants range from US $\$ 10,000$ to US $\$ 140,000$. ISP fellowships have helped to produce 58 doctorate and 246 master's theses, and 328 papers in international journals.

\section{THE RISE PROGRAMME}

Past experience has shown the power of knowledge-sharing. Such sharing serves as the basis for the RISE programme developed by the SIG, funded by the Carnegie Corporation and cosponsored by the Institute for Advanced Study in Princeton. RISE is built on earlier experience with the Millennium Science Initiative, funded by the World Bank.

The objective of RISE is to prepare PhD-level scientists and engineers in sub-Saharan Africa through university-based research and training networks. The programme will support networks in at least three countries. Each network will be expected to grant a minimum of $15 \mathrm{PhD}$ and master's degrees over 4-6 years.

Three networks will receive approximately US $\$ 800,000$ over 30 months, with funding likely to continue for an additional 3 years. Both TWAS and the Stockholm-based International Foundation for Science (IFS) have agreed to supplement Carnegie's funding for basic science and applied science, respectively. Agriculture and biosciences were not included because many other programmes already cover these fields.

RISE is competitive. The programme received 48 proposals from scientists in 29 countries, and has appointed an international selection committee to choose three of these for funding and to evaluate the initiatives once they are underway. The proposals vividly illustrate how many functional and imaginative African networks already exist in such critical areas as clean drinking water, renewable energy, geophysics, information technology and natural products. The impulse to collaborate is strong, and applicants appear to welcome the opportunity to form partnerships with groups that have complementary expertise.

If there is a weakness in the proposals, it is a lack of access to the private sector and other potential partners outside academia. This is to be expected in countries where technical skills at all levels have been neglected for many years. That is why the strengthening of universities must be considered as just a first step in capacity building.

In February 2007, the World Bank, which has recently taken a leadership role in STI capacity building in Africa, held a global forum in Washington, DC, where many African scientists and development experts spoke about their experiences. Speakers emphasized innovative ways to develop technical and vocational skills, to boost the private sector's capacity to find, adopt and adapt existing technologies that are not being fully utilized, to use these skills and technologies to generate more knowledgeintensive value-added goods and services, and to build post-primary education and scientificresearch systems that contribute in meaningful and measurable ways to the national development strategy.

Conference participants agreed that knowledge-intensive goods and services should not be confused with high-technology goods and services. For example, the production of flowers and salmon can be more knowledge-intensive than assembling computers from imported components. That is, the capacity to absorb and diffuse existing knowledge is at least as important as the capacity to produce new knowledge.

\section{KNOWLEDGE FIRST}

There can be no economic advancement without the creation of knowledge. Yet knowledge becomes economically valuable only when it is disseminated in a useful form. Each country must develop its own endemic capacity if it is to stay at the forefront of modern science, but it must also develop mechanisms for disseminating and using that knowledge to serve the interests of itself and its region.
These dual objectives must be linked if sub-Saharan Africa is to compete globally. The success of the networks described above will rest largely on the determination of African governments. While many institutions and individuals will play essential roles, only governments can build and sustain the foundation of basic science that is needed to anchor and stimulate economic growth, and to enrich society.

Once a strong platform in basic science is in place, sub-Saharan Africa will be ready to take full advantage of its rich mineral resources, maturing political institutions, abundance of native talent and eager-to-help diaspora.

From such a platform, young Africans will be able to earn degrees in mathematics, physics, chemistry and biology that will help sub-Saharan Africa to assume its rightful place at the table of nations. Young Africans, moreover, will be able to probe the 'dazzlement' of science, narrowing the gap between the North and the South, and bringing sub-Saharan Africa closer to Abdus Salam's vision of attaining "a bounty and a grace" for which thanks can be rendered "with a humble heart".

Phillip A. Griffiths (TWAS Associate Fellow 2000) is professor of mathematics and director emeritus at the Institute for Advanced Study in Princeton, New Jersey, USA.

\section{VIEWPOINT I Ahmed Zewail Money counts but merit and freedom count even more}

In too many developing countries, educational systems are poor, opportunities limited, pay inadequate and the quality of life wanting. Under such circumstances, it is not surprising that scientists in developing countries often seek their future elsewhere. Science, after all, is an international enterprise that rewards performance, and scientists are bound to go where the prospects for success - both professional and personal - are the brightest. Yet, we now know that things can change quickly. South Korea, an impoverished nation virtually without science in the mid 1960s, has grown into a scientific powerhouse with the world's thirteenth largest economy. China, an emerging economic power, is building its future on a strong foundation in science and technology. So, too, are India, Brazil and a growing number of other nations, including Malaysia, Singapore and Vietnam. Countries in the Persian Gulf have embarked on ambitious programmes to reform education and expand scientific and technological infrastructures. The Qatar Foundation for Education, Science and Community Development has forged partnerships with some of the world's most respected universities, including Georgetown University's School of Foreign Service and Cornell Medical College. Kuwait and the United Arab Emirates have launched new initiatives for the reform of education and research. Saudi Arabia has broken ground for the King Abdullah University of Science and Technology (KAUST) and has granted it a US\$10 billion endowment. Egypt has renewed discussions to construct a worldclass university focusing on science and technology. There is no reason why the Arab and Muslim world, which has yet to participate fully in our world of knowledge, cannot develop the means to do so. It requires an emphasis on merit, sustained financial support and a commitment to freedom of thought. That is easier said than done - but that does not mean it cannot be done. The current situation is undoubtedly difficult in many developing countries, both for science and society. But I am optimistic by nature. I believe in the power of the human mind, and that means forward-looking change is possible.

Ahmed Zewail (TWAS Fellow 1989) is Linus Pauling chair professor of chemistry and professor of physics at the California Institute of Technology in Pasadena, California, USA. He received the Nobel Prize in chemistry in 1999. 